\title{
Entre jogos: \\ Una discusión poscolonial sobre la regulación de la Capoeira
}

\author{
Entre jogos: \\ A poscolonial discussion about the regulation of Capoeira
}

iD Raimundo Ferreira de Sousa

Centro Universitário Estácio de Sá Belo Horizonte Mg

Correo:mestreray@hotmail.com

Resumen: El artículo presenta las discusiones suscitadas por la propuesta de ley PL 3640/2020, presentada por el Diputado Lafayette de Andrada, la cual, tiene como fin regular las actividades profesionales de las personas que practican Capoeira. Esta discusión se suma a los múltiples intentos que se han impulsado por regular la práctica de la Capoeira. Por ello, el estudio se funda en un análisis poscolonial sobre los intentos de regulación de la Capoeira que han sido propuestos por las autoridades del gobierno brasileño. A partir de lo cual, se puede concluir que las relaciones políticas entre las autoridades y las personas que practican Capoeira muestran la pervivencia de prácticas colonialistas en torno al control de los saberes populares afrobrasileños.

Palabras clave: capoeira, cultura popular, patrimonio inmaterial, poscolonialidad, regulación

\begin{abstract}
This article shows the discussion motivated for the law initiative PL 3640/2020. The main proposal of this initiative is to regulate the professional practice of Capoeira. So, this fact is the latest episode of a many other attempts to regulate the professional practice of Capoeira. In consequence, from a poscolonial perspective the article makes an historical revision about the attempts to regulate the Capoeira, highlighting the tensions between Brazilian government authorities and the professional groups of Capoeira. In conclusion the political relations between authorities and Capoeira's groups are one example of the colonial practices related to political control of popular knowledge of afro Brazilian population.
\end{abstract}

Keywords: capoeira, intangible heritage, poscolianity, popular culture, regulation

Ferreira-de-Sousa, R. (2021). Entre jogos: Una discusión poscolonial sobre la regulación de la Capoeira. [Entre jogos: A poscolonial discussion about the regulation of Capoeira]. Forhum International Journal of Social Sciences and Humanities, 3(4), 81-96. https://doi.org/10.35766/j.forhum2021.04.03.7 


\section{Introducción}

El 2 de julio de 2020, el diputado Lafayette de Andrada, vice representante de la facción republicana brasileña presentó ante el pleno del Congreso Nacional Brasileño, la propuesta PL 3640/2020, la cual, propone una política de reglamentación de la profesión de capoerista. La propuesta consta de diez artículos, a lo largo de los cuales, se propone que la profesión de capoerista sea reconocida bajo los estatutos del artículo $5^{\circ}$, fracciones VIII y XIII de la Constitución Federal Brasileña, las cuales, refieren que:

Artículo 5: Todos son iguales ante la ley, sin distinción de cualquier naturaleza, garantizándose a los brasileños y a los extranjeros residentes en el País la inviolabilidad del derecho a la vida, a la libertad, a la igualdad, a la seguridad y a la prioridad, en los siguientes términos: Fracc XVIII.- nadie será privado de sus derechos por motivo de su creencia religiosa o por su convicción filosófica o política (...) Fracc XIII.- Es libre el ejercicio de cualquier trabajo, oficio o profesión, cumpliendo las calificaciones profesionales que la ley establezca (Const, 1988).

Con base en estos principios, la propuesta señala las directrices a partir de las cuales, las personas dedicadas a la profesión y a la enseñanza capoerística, según las jerarquías que cada estilo y grupo, desde el grado de Monitora o Monitor hasta el de Mestre o Mestra, podrían ejercer su oficio de enseñanza en apego a la ley, con las garantías, derechos y obligaciones que el reconocimiento de la ley PL 3640/2020.

El Diputado de Andrada justifica esta iniciativa de regulación en el reconocimiento del pasado de opresión en el que nació la Capoeira, así como el desarrollo y crecimiento que ésta ha tenido desde tiempos de la esclavitud, la cual, se ha extendido a nivel mundial. De tal modo, en la propuesta, de Andrada propone que "...con su expansión, importancia y crecimiento social, se hace necesario que las normativas legislativas acompañen al progreso de la Capoeira" (PL340/2020, 2020, p. 3). Para cumplir con este fin, y dotar de derechos y obligaciones a las personas profesionales de la Capoeira, el Diputado promueve el reconocimiento legislativo de esta profesión.

En respuesta a la propuesta, diversos grupos y asociaciones de personas practicantes de capoerista, reunidas en torno a la Rede Nacional de Ação da Capoeira (RENAC) se manifestaron en contra de la propuesta y, hasta el 1 de octubre, decían haber reunido 5 mil firmas en contra de la propuesta de Andrada (RENAC, 2020). La RENAC manifestaba dos puntos de controversia, el primero, referente al carácter patrimonial que le otorgaron el Instituto do Patrimonio Histórico e Artístico Nacional (IPHAN) y la Organización de las Naciones Unidas para la Educación, la Ciencia y la Cultura (UNESCO) a la Capoeira. El segundo punto de defensa se apoyaba en la importancia que ha tomado la Capoeira en los últimos tiempos no justifica que ahora, se le busque normar con base en los estatutos legislativos. Por último, se señala la imposibilidad de entender la Capoeira sólo como una práctica deportiva, pues, ésta entraña una diversidad que la hace ser danza, arte, cultura, pero, sobre todo, un arte de resistencia y libertad.

En suma, las personas profesionales de la Capoeira reclaman su autonomía e independencia como un grupo profesional que ha crecido y ha mantenido su desarrollo sin el apoyo de las instancias gubernamentales, incluso, pese a las propias restricciones de las autoridades. Asimismo, reclaman sus derechos como sujetos de las garantías de apoyo y preservación cultural que les inviste las declaratorias nacionales y mundiales de las que han sido parte. En conclusión, desde la perspectiva de las personas profesionales de la Capoeira, no resulta necesario que sean tutelados por las 
normatividades del Estado brasileño, al menos no, sin que las personas practicantes sean participes activos de estas normatividades.

La polémica que ha reanimado la propuesta del diputado de Andrada permite observar la contemporaneidad sobre la tensión que existe entre autoridades y capoeristas en torno a la regulación de la práctica de esta arte de origen afrobrasileño. En este sentido, la intención del trabajo es cómo, a través de esta incesante polémica, se pueden apreciar algunas constantes históricas que nos permiten identificar la existencia de una intención estatal por capitalizar las riquezas históricas y culturales que genera este arte afrodescendiente, como la forma en la que las personas practicantes han resistido a los múltiples embates del Estado brasileño por regular su práctica (Costa, 2010; Lube, 2011). De tal modo, se aprecia que la lucha por la libertad que se encuentra en el sustrato de la Capoeira no ha desaparecido, sino que se ha trasladado a otras arenas de combate y resistencia, en este caso, a las arenas jurídicas (Fonseca, 2014; Serna, 2018).

Con base en esta premisa, el artículo tiene como objetivo construir un recuento histórico sobre los intentos de regulación de la Capoeira. El propósito de este recuento es identificar las constantes en la disputa entre autoridades y grupos de Capoeira. Dentro de esta tensión, es un objetivo del trabajo mostrar las voces de la resistencia que han manifestado distintos Mestres de Capoeira en torno a la propuesta de Lafayette de Andrada. Con ello, se logra exponer que existe una constante en cuanto a las prácticas políticas de dominación que sostienen las regulaciones de la Capoeira (Carvalho, 2010). Un aspecto que, en perspectiva comparativa, permite analizar la política cultural sobre la patrimonializarían de los espacios y prácticas culturales en América Latina (Zanirato, 2007).

\section{Desarrollo}

Regulaciones y resistencias a lo largo de la historia. Una propuesta analítica.

Es una práctica de la racionalidad moderna pensar los fenómenos desde una perspectiva teleológica, es decir, que todo desarrollo lineal del tiempo apunta hacia un mejoramiento de las condiciones sociales. No obstante, desde una perspectiva sociológica (Elias, 2009) los procesos de desarrollo de los fenómenos sociales a lo largo del tiempo no obedecen a desarrollos lineales, ni significan que el paso el tiempo apunte hacia mejorar sus condiciones de posibilidad. Para Elias, existen avances y retrocesos dentro de los procesos sociales, incluso algunas constantes. Esto podría estar sucediendo en las relaciones interraciales, pues en todo el mundo se han registrado diversos sucesos que evidencian la permanencia de prácticas de odio en contra de las personas afrodescendientes. Acciones que, en ocasiones han tenido lamentables consecuencias y en otros casos, son simbólicas, pero no menos alarmantes.

Podríamos nombrar a los recientes asesinatos de personas afroamericanas a manos de las fuerzas policiacas de los Estados Unidos, como un ejemplo de este episodio que ejemplifica la lamentable permanencia de la violencia racial en contra de las poblaciones afrodescendientes. Pero, debido a que es un ejemplo más cercano al tema de este trabajo, valdría la pena recordar el asesinato de Mestre Moa do Katendê, acontecido el 8 de octubre de 2018, debido a una rencilla por temas políticos en el contexto de las elecciones presidenciales en las que Jair Bolsonaro ganó la elección presidencial por el partido social liberal de Brasil.

Aunque es polémico el tema presidencial en Brasil, después de lo acontecido durante el Período de Dilma Rousseff, es necesario ubicar la situación de la Capoeira y el asesinato de Mestre Moa do Katendê, en un contexto en el que, en gran parte de la región sudamericana, y en otras partes del 
mundo, se comienza a registrar el ascenso de los gobiernos de la ultra derecha que atentan en contra de las libertades y derechos que se habían ganado durante los gobiernos de la izquierda progresista en favor de los grupos más desfavorecidos. En el caso concreto de la Capoeira, por su pasado vinculado con la resistencia y la lucha en contra de la esclavitud afrobrasileña, no es casual que haya sido objeto del renacido odio racial promovido por los gobiernos de ultraderecha como el que encabeza Bolsonaro.

No puede escapar este tema político de nuestra agenda analítica, pues, este es el marco en el que se construyen las políticas y propuestas de leyes que emanan desde el gobierno. Esta es la óptica desde la cual se construye la óptica del gobierno brasileño en nuestros tiempos. En este contexto se enmarca el reciente intento de regulación de la Capoeira, acto se que se podría interpretar como una afrenta simbólica en contra de las poblaciones afrodescendientes, pues, revivió las disputas por el ejercicio de una práctica cultural de origen afrobrasileño, como lo es la Capoeira. Para entender este razonamiento, se considera importante revisar la historia de los instrumentos jurídicos que se han promulgado en torno a la regulación de esta arte. Acto seguido, es necesario destacar aquellas constantes que podrían encontrarse en los distintos instrumentos jurídicos. En última instancia, estos pasos permiten analizar las condiciones que caracterizan a las relaciones interraciales entre las autoridades y las personas afrobrasileñas.

Desde esta perspectiva, los instrumentos jurídicos son referentes que norman las acciones de las personas y reflejan los valores de los agentes de gobierno que están detrás de su elaboración. Valores que más que ser una cuestión subjetiva, son el reflejo de las condiciones históricas de las relaciones en torno a las poblaciones afrobrasileñas. De tal forma, la propuesta es observar las relaciones sociojurídicas desde una óptica poscolonial (Costa y Boatcă, 2010), en este sentido:

el término "poscolonial" también se refiere a la reconfiguración de las relaciones económicas, sociales y políticas que el colonialismo ha detonado en las antiguas colonias y metrópolis, así como a la tensión entre el poder y la producción del conocimiento en el contexto de relaciones imperiales (p.337).

Esto es importante, pues la perspectiva analítica de este trabajo, no termina ni se limita a un recuento intelectual sobre los acontecimientos, documentos y fechas que conforman la historia de la regulación de la Capoeira, si no que, la óptica analítica busca destacar las relaciones políticas de desigualdad que se construyeron en tiempos coloniales y que persisten como un andamiaje que estructura, en este caso, las relaciones de producción y pertenencia del arte y saber de raíz afrodescendiente. En este sentido, los intentos de regulación de la Capoeira se podrían interpretar como un fenómeno que evidencian la permanencia de las condiciones de desigualdad y dominación que caracterizaron a las relaciones sociales hacia las personas afrobrasileñas en tiempos de la colonia (Costa y Boatcă, 2010).

El origen de esta relación socio jurídica inicia con la promulgación del decreto real de liberación de la Capoeira que realizó la Princesa Isabel el 13 de mayo de 1988. Un año después, al caer la monarquía de Brasil y al ascender el gobierno republicano, se suscitaría un cambio radical sobre la perspectiva jurídica en torno a la Capoeira. Pues, en el Código penal de 1889, se decretaría la prohibición y castigo de las personas que fueran sorprendidas practicando Capoeira. Así lo atestiguan los artículos 402 y 404 contenido en el capítulo XIII de este Código penal, en los que se tipifica a las personas practicantes de Capoeira como parte de las poblaciones que podrían ser condenadas hasta por un periodo de tres años de prisión en los presidios construidos en la isla de Fernando de Noronha.

Este vestigio histórico pareciera que se encuentra en el fondo de la perspectiva regulatoria de la Capoeira, pues Andrada pertenece a la facción republicana de la Cámara de Diputados de Brasil. 
Por su parte, intentos previos de regulación de la Capoeira, también han sido formuladas por parte de la facción republicana, como fue el caso de los intentos de regulación que se suscitaron durante el 2008-2009 en los textos de las propuestas ley: 2.85812, el proyecto de ley 5.222/09. Entonces, es factible pensar que existe un reflejo de las posiciones políticas y los valores de clase en los intentos de regulación de la Capoeira, con lo cual, se podría entender la intención de reproducir las relaciones de dominación que caracterizaron al período posterior al régimen colonial. Así, un primer paso dentro del análisis es no pensar los instrumentos jurídicos como productos libres de valores, como se piensa en la teoría positiva del derecho.

Por su parte, se encuentra otra perspectiva de la regulación que se enfoca en los bienes patrimoniales y en el empoderamiento de los grupos socioculturales, esa es la perspectiva que imperó a partir del gobierno de Lula da Silva y se materializó en el Programa Cultura Viva. Un programa que fue implementado el 15 de agosto del 2006 por la MinC, con el propósito de promover la Capoeira reconociéndola como “...una de las principales expresiones de difusión de la cultura brasileña por el mundo, sin nunca haber recibido apoyo gubernamental "(Nunes, 2000. Citado por Costa, 2010, p. 294). Así, el programa Cultura Viva buscó estimular el desarrollo de los trabajos culturales realizados en las comunidades a partir de fondos de participación destinados a la sociedad civil (Costa, 2010, p. 293). Sin embargo, el proyecto fue inestable ya que no se realizó en sus ediciones 2008, 2009 y 2010 (Costa, 2010).

Ese es el otro frente de la regulación de las actividades culturales afrobrasileñas como la Capoeira, en el que se otorgan recursos limitados a las personas que son las detentoras de estas prácticas afrobrasileñas. Al tiempo en el que se les adentra en una lógica burocrática que resulta ajena para gran parte de estas personas, como lo identificó Fonseca (2014) y que lejos de reducir las desigualdades acentúan las diferencias y limitan la ejecución de las practicas. Es decir, la perspectiva progresista hacia la Capoeira sigue conceptualizando a las personas capoeristas como sujetos pasivos de las políticas culturales y no como agentes activos y autónomos, con la capacidad de regular y administrar sus propias riquezas culturales.

Así, la arena por la regulación de la Capoeira, históricamente se ha compuesto por tres frentes, por un lado, el frente liberal republicano que continua con las políticas de castigo y persecución a las personas capoeristas, a través de las cuales se busca regular la profesión del capoeristas. Una segunda perspectiva, es la de los intentos de regulación progresista que otorgan políticas económicas a los profesionales de la Capoeira desde una perspectiva paternalista. Una tercera perspectiva es la de las personas profesionales de la Capoeira, quienes defienden la autonomía de un arte que es herencia de una lucha centenaria por la libertad. Estos tres frentes se podrían decir que constituyen la arena que se disputa el gobierno y la regulación de la Capoeira en Brasil.

Una arena que pasa por la óptica crítica de una colonialidad del poder (Mignolo, 2010), pues, las políticas y propuestas de ley que buscan regular a la Capoeira, caben dentro de "...la compleja o patrón de poder sustentado en dos pilares: el conocer (epistemología), entender o comprender (hermenéutica) y el sentir (aesthesis)" (p. 12). Desde esta perspectiva, la atención de las leyes va más allá de su constructo jurídico y se centra en las consecuencias de las reglamentaciones dentro de un marco de relaciones políticas coloniales que han sido marcadas por la desigualdad racial, así, como se mostrará, la insistencia por regular la Capoeira, atenta en contra de las epistemologías afrobrasileñas que fundamentan la enseñanza de la Capoeira como en contra de los Mestres y Mestras que encarnan estos saberes. Del mismo modo, las regulaciones implican una violencia epistémica en la medida en la que obligan a trasladar la transmisión de saberes de la Capoeira a un lenguaje 
burocratizado de los programas y leyes que suponen la profesionalización de la enseñanza de esta arte.

Así, desde esta perspectiva poscolonial, una de las principales preocupaciones en torno a la regulación de la Capoeira, radica en señalar las condiciones e impedir la posibilidad de que se desarrollen prácticas de extractivismo epistémico (Grossfoguel, 2016), lo cual, se entiendo como:

El «extractivismo epistémico» expolia ideas (sean científicas o ambientalistas) de las comunidades indígenas, sacándolas de los contextos en que fueron producidos para despolitizarlas y resignificarlas desde lógicas occidentalo-céntricas. El objetivo del «extractivismo epistémico» es el saqueo de ideas para mercadearlas y transformarlas en capital económico o para apropiárselas dentro de la maquinaria académica occidental con el fin de ganar capital simbólico. En ambos casos, se los descontextualiza para quitarles contenidos radicales y despolitizarlos con el propósito de hacerlos más mercadeables. (p. 133).

Sobre estas perspectivas analíticas poscoloniales y sobre los hechos históricos que han marcado las relaciones entre el gobierno y las personas profesionales de la Capoeira, la intención de este trabajo es adoptar una posición analítica, como política, para analizar las prácticas que reproducen las relaciones políticas de dominación en contra de las personas afrodescendientes que practican Capoeira. Esta posición no puede ser diferente, pues desde la raíz histórica de los tiempos de la esclavitud, el propósito de las prácticas socioculturales de origen afrobrasileño era mantener vivos los vestigios culturales de las poblaciones africanas que sufrieron el violento desarraigo que supuso la esclavitud (Rector, 2008).

\section{Una polémica incesante: breve recuento sobre los intentos por regularizar a la Capoeira}

Con base en lo anterior, la tensión política que representa la propuesta de ley del Diputado de Andrada y la consecuente resistencia de las personas profesionales de la Capoeira, es la representación actual de una polémica antigua, a través de la cual, podemos apreciar dos perspectivas antagónicas en torno a lo que es la Capoeira. Por un lado, las personas practicantes como detentoras de un saber de resistencia y libertad, que defienden la ancestralidad de su saber; y por el otro lado, el Estado que siempre criminalizó y prohibió la práctica de la Capoeira, pero que, desde el proceso de constitución de la identidad del Estado brasileño, buscó apropiarse de la Capoeira (Fonseca, 2008, p. 9).

La postura de apropiación cultural por parte de las autoridades quedó evidenciada desde que se buscó reducir a la Capoeira a su ámbito marcial y se quiso introducir como sello distintivo de la milicia brasileña a través de los manuales de entrenamiento corporal (Fonseca, 2008). Como lo identificó Fonseca (2008) en el caso de:

Coelho Neto llegó inclusive a defender la enseñanza de la Capoeira en las escuelas y en las Fuerzas armadas, sirviendo, en esta última, como un método de defensa corporal. Otro defensor de la Capoeira como un deporte nacional fue Aníbal Burlamaqui (1928), que llega inclusive a publicar un manual em el cual propuso un reglamento para la Capoeira, así como criterios para futuras competiciones (p. 5-6)

Esta alusión histórica nos permite ilustrar cómo, después de la descriminalización de la Capoeira, se buscó reducir su riqueza cultural al plano deportivo, y con ello, regular la práctica y enseñanza de la Capoeira (Costa, 2010). Siguiendo esta tónica, los intentos por regular la práctica y enseñanza de la Capoeira se han multiplicado a lo largo de las décadas (Pires y Pinheiro, 2009, p. 4950). Con respecto a lo anterior, Costa (2010) identificó cinco aspectos que posibilitaron la concepción 
de la Capoeira sólo desde el plano deportivo, una vez que esta práctica se extendió más allá de las fronteras de Salvador, Bahía, hacia el final de los años sesenta:

Posiblemente, cinco factores irán a contribuir para la inserción de la capoeira en la sociedad, entendida mayoritariamente como una práctica deportiva: la introducción de la capoeira en las universidades, primero, como una disciplina denominada práctica deportiva e, posteriormente, como una disciplina curricular de la formación del profesorado de Educación Física (De Bahía a Río de Janeiro); la inserción de la capoeira en la Federación de Pugilismo; la inmigración de Mestres bahianos para Sao Paulo y Rio [de Janeiro]; y el reconocimiento como un deporte, a través de una ordenanza de 1972, por el Ministerio de Educación y Cultura (MEC) y el Programa Nacional de Capoeira (PNC), desarrollado por el, entonces, Ministerio de Educación e del Desarrollo (p. 290).

Por el lado de las personas profesionales de la Capoeira, si bien, ha existido una facción que ha apoyado los proyectos de regulación deportiva promovidos por el Estado, en el grueso de capoeristas se ha mantenido renuente a las propuestas de regulación, pues, a pesar del ofrecimiento del reconocimiento legal por parte de las autoridades, las personas capoeristas se resisten a que la riqueza de la Capoeira se reduzca a una sola expresión marcial o deportiva, en detrimento de toda la riqueza cultural que entrañan los rituales que componen y fundamentan su práctica (Fonseca. 2008, p. 18; Talmon-Chvaicer, 2008, p. 2). Aunado a ello, existe la autonomía relativa que buscan preservar los Mestres y Mestras de Capoeira como las únicas personas autorizadas para ejercer y facultar el ejercicio profesional de capoerístico.

El plano de la regulación laboral es un tema delicado, pues, si bien es un hecho de que la enseñanza de la Capoeira se encuentra en un espacio gris en términos de acceso a la seguridad social, el sistema de ahorro para la vejez, el acceso a los créditos de vivienda y demás características del empleo digno y pleno como lo signan las instituciones encargadas de vigilar el trabajo a nivel mundial. En conocimiento de estas carencias y vulnerabilidades, las autoridades del Estado brasileño han ofrecido que, con la regulación de la capoeira, las personas profesionales pueden tener acceso a todos los derechos que garantiza el pleno empleo. No obstante, a cambio de ello, el Estado busca tutelar la profesionalización de las personas capacitadas para la enseñanza de la capoeira. Aspecto al que las personas practicantes se han rehusado.

La reticencia obedece a que, según las características de un saber ancestral que implica un amplio conocimiento de la historia, la música, los movimientos, las danzas y demás fundamentos que sostienen el saber de la capoeira; esto no puede ser aprendido si no es por medio de la vivencia dedicada por varias décadas. Un aprendizaje vivo que, arguyen las personas profesionales de la capoeira, no puede ser reducido a un período de capacitación universitaria como lo han propuesto algunas iniciativas de regulación, como fue el caso de la serie de la propuesta de ley 2.85812 propuesta por el diputado Carlos Zarattini, a la cual, le sucederían las propuestas de ley. 2.858/08 y el proyecto de ley 5.222/09, propuesto por la Diputada Lídice da Mata. El conjunto de estas propuestas legislativas buscaba promover una ley que regulará la profesión de capoerista, al igual que otras profesiones deportivas y marciales.

A contrapelo de esta tónica reduccionista con respecto a la Capoeira, a lo largo de todo el período de gobierno de Lula da Silva, del 2003 al 2010, se promovió una política patrimonialista por medio del trabajo del Ministerio de Cultura (MinC) que buscó construir una relación de trabajo entre las instancias del gobierno y los grupos de capoeristas, respetando la ancestralidad de la capoeira (Costa, 2010; Fonseca, 2014), así como la autonomía de los profesionales de esta arte. El gran eje de este trabajo fue el apego que la política cultural brasileña mantuvo con las directrices de la defensa 
del patrimonio histórico y cultural que fueron marcadas por la UNESCO (Serna, 2018). Esta política cultural se reflejaría en tres programas: Puntos de Cultura (Costa, 2010, p. 293), el Programa Capoeira Viva (Costa, 2010, p. 294) y otras políticas de patrimonio cultural.

No obstante, a pesar de las buenas intenciones del gobierno brasileño, la política cultural de apoyo y preservación de la capoeira, así como su apoyo a las personas profesionales de la capoeira, fracasaría debido a la falta de cohesión de los distintos programas, la opacidad en las reglas de operación, la poca claridad de las normatividades para la aplicación de los fondos, las desigualdades en el acceso y aplicación de las convocatorias por parte de las personas profesionales de la Capoeira y la falta de seguimiento de los programas. El caso del programa Capoeira Viva, es ilustrador, pues, fue un proyecto inestable ya que no se realizó en sus ediciones 2008, 2009; y, estaba en ascuas de realizarse en 2010 (Costa, 2010). Por ello, dejaron de ser parte de la política cultural de los gobiernos posteriores a Lula da Silva (Costa, 2010, p. 301).

Pese a las inconsistencias administrativas en la implementación de esta política cultural, se continuó por la senda patrimonialista, al reconocer jurídicamente a la Capoeira como Patrimonio inmaterial de la Humanidad (Fonseca, 2014, p. 111). Asentado en el proceso número 01450.002863/2006-80, n 031/08 en el que obra el "Registro de la Capoeira como Patrimonio Cultural de Brasil". Este reconocimiento se extendía hacia las personas profesionales de la Capoeira, pues, se buscaba garantizar cuatro puntos: 1) otorgar una providencia especial para las personas profesionales de la Capoeira en edad más avanzada 2) Establecer un programa de incentivos de la Capoeira en el mundo 3) la creación de un centro nacional de referencia de la Capoeira y 4) La planeación para el manejo de las plantaciones de biriba, madera con la que tradicionalmente se hacen los berimbaus. (Costa, 2010, p. 300-301).

Sin embargo, a pesar de todos los esfuerzos normativos y a la buena intención de la política patrimonialista de las declaraciones nacionales e internacionales, lo cierto es que las personas profesionales de la Capoeira siguen viviendo en condiciones de empleo precario. En tanto la promoción de la Capoeira sigue careciendo de una política cultural seria y constante que corresponda con el aprecio cultural e histórico que se manifiesta en los decretos patrimoniales. De hecho, las propuestas de ley como la que representa la promovida por el diputado de Andrada, son una muestra de la poca efectividad que estas declaratorias han tenido en el aspecto jurídico y laboral de las personas profesionales de la Capoeira, pues, se les busca tutelar como una actividad deportiva y profesional más. En este sentido, la propuesta de ley PL 3640/2020 es un franco retroceso con respecto a los derechos y garantías que supuso la política cultural patrimonial durante el período de gobierno de Lula.

\section{Mandingas jurídicas: los argumentos de la RENAC}

Las controversias jurídicas en torno a la Capoeira, como la forma en la que se han ignorado los reconocimientos sobre las declaratorias patrimoniales de la Capoeira y de sus profesionales, nos habla sobre la prevalencia de las desigualdades políticas entre las autoridades y las personas que detentan los saberes de la Capoeira. Al respecto, las resistencias de las personas que practican Capoeira se han trasladado, de las resistencias físicas, al plano de las luchas políticas y jurídicas en defensa de la libertad y autonomía de la profesión de la Capoeira.

Así lo representan los manifiestos y acciones de la $R E N A C$, quienes promovieron una serie de manifiestos en los cuales, muestran su descontento en contra de la regulación propuesta por de Andrada. Lo que destaca en estos textos, es la prosa jurídica que manejan los escritos, a través de los cuales, las personas practicantes de capoeira, más de 5 mil personas que se adhieren al movimiento, 
denuncian que la propuesta de regulación promovida por el diputado no respeta las garantías constitucionales y otras leyes que protegen los derechos de las personas practicantes de Capoeira.

El argumento central que busca defender la $R E N A C$, es que se conceptualice a la Capoeira como:

... una práctica multidimensional $\mathrm{y}$, sobre todo, una referencia cultural de la sociedad brasileña. La Capoeira puede ser tanto danza, lucha y deporte, como también es cultura, pasatiempo, medio de socialización, instrumento de educación popular, forma de transmisión de saberes e de la memoria ancestral, símbolo de afirmación identitaria, entre otros (RENAC, 2020).

Este razonamiento está apoyado en una serie de instrumentos jurídicos, teniendo como primera línea de referencia a los reconocimientos patrimoniales del Oficio dos Mestres de Capoeira e da Roda de Capoeira como Patrimônio Cultural do Brasil, así como el Reconhecimento da Roda de Capoeira como Patrimônio Cultural Imaterial da Humanidade otorgado por la UNESCO el 26 de noviembre de 2014. En ese orden jurídico, el documento, también evoca el posicionamiento que realizó el IPHAN presentado frente al Senado federal el 7 de mayo de 2014, el cual fue archivado en el PLC 031/2009. Así mismo, se menciona el artículo 22 fracción primera del Estatuto da Igualdade Racial, que señala que "...la actividad de capoeirista será reconocida en todas las modalidades que se manifiesta, se deporte, lucha, danza o música, siendo libre el ejercicio en todo el territorio nacional".

Con base en estas referencias jurídicas, si bien la $R E N A C$ rechaza las propuestas regulatorias que representa el proyecto de ley PL 3640/2020, esto no quiere decir que se rehúya de una identidad jurídica que tutele y regule el ejercicio profesional de la Capoeira. Por el contrario, la RENAC manifiesta su apego en defensa del proyecto de ley PL 453/2020, el cual “....establece las directrices y las bases de la educación nacional para incluir la práctica de la Capoeira en el grado curricular de los niveles básicos y medios, en la escuela pública" (RENAC, 2020). Así mismo, la RENAC manifiesta la defensa del texto original del proyecto de ley 1966/2015 que fue aprobado por el Senado Federal y que reconoce el carácter multidimensional de la Capoeira, contemplando:

...todas las vertientes de la Capoeira de Brasil, no comprometiendo la libertad, la autonomía e la tradición de la Capoeira y de los y de las capoeristas, los verdaderos detentores de la transmisión oral y corporal de este importante instrumento secular de inclusión social y cultural de la sociedad en Brasil y en el mundo. (RENAC, 2020).

De tal forma, lejos de pensar que existe una renuencia a la regulación por parte de los grupos y personas profesionales de la Capoeira, lo que existe es una resistencia jurídicamente fundada en cuanto a los derechos y garantías que ya han sido promulgadas para la atención estatal de la Capoeira, pero que, no han sido debidamente atendidas e instituidas por las autoridades de los gobiernos brasileños.

Por su parte, la omisión de estas promulgaciones y decretos nos hace pensar que las regulaciones que se buscan promover por parte de la PL 3640/2020 responden a un profundo desconocimiento del quehacer de la Capoeira, apegándose más a un interés por regular la Capoeira con fines mercantiles y económicos, en favor de un grupo legislativo que no parece estar inserto dentro de la práctica y enseñanza de esta arte afrobrasileña. Así lo denuncia la melodía que canta

Mestre Camaleão como estandarte de la RENAC (2020):

Andam dizendo por aí. Andam dizendo por aí

Que uma lei já se formo para regulamentar a Capoeira

Essa coisa se tornou.

Quem levo essa lei, ¡Ei! Quem levo essa lei ¡Oh, ia, ia! 


\section{Capoeira não jogo. Capoeira nasceu no gueto e o mundo já ganho \\ A capoeira já está livre de esse sistema opressor ${ }^{1}$}

$\mathrm{Al}$ respecto, es necesario destacar que el gremio capoeristico no se encuentra en contra de las regulaciones ni en contra de que la práctica sea tutelada de manera jurídica por las autoridades del gobierno brasileño. Lo que sí es manifiesto, es la oposición en contra de las normatividades que no respetan la autonomía, libertad, independencia y derechos por los que han luchado las personas practicantes y profesionales de la Capoeira; aspectos que, incluso, tienen un respaldo jurídico a nivel nacional e internacional. Es así como, lo que exigen las personas que integran el gremio, es que se constituyan instrumentos jurídicos que velen por estos derechos y garantías, los cuales no pueden ser propuestos ni construidos sin la participación de las personas profesionales de la Capoeira, quienes son las afectadas o beneficiarias directas de las legislaciones creadas.

Por otro lado, la insistencia de las autoridades por regular la Capoeira, expidiendo propuesta de leyes que no son requeridas por las propias personas a quienes van dirigidas, nos hace recordar aquella anécdota que relata el encuentro entre Alejandro Magno y Diógenes. Se cuenta que, de camino a la India, Alejandro Magno se encontró en su andar con Diógenes. El Conquistador, sabedor de la fama que tenía el filósofo, se le acercó y le dijo: "Quería demostrarte mi admiración. Pídeme lo que tú quieras, puedo darte cualquier cosa que desees" -a lo que Diógenes, respondió- "Por supuesto. No seré yo quien te impida demostrar tu afecto hacia mí. Querría pedirte que te apartes del sol. Que sus rayos me toquen es, ahora mismo, mi más grande deseo".

El sentido político de Diógenes que, como todo cínico (Martínez, 2015) encuentra un camino rebuscado para plantear su crítica al poder, es muy parecido a las formas que cobra la mandinga en la cultura de la Capoeira, pues, Diógenes encuentra una forma velada pero directa para decirle a Alejandro Magno, que no su ayuda no es necesaria. Eso mismo es lo que plantea el gremio capoerístico con respecto a este tipo de legislaciones que, tras el discurso de beneficiar a las personas profesionales de la Capoeira, buscar regular su práctica.

Por su parte, la relación del diálogo entre los poderosos, encarnados por Carlo Magno, y las personas admiradas, pero fuera de lógica política, como sería Diógenes, nos muestra cómo prevalece una perspectiva colonial de parte de las autoridades con respecto a la Capoeira. Pues, se parte del principio de que las personas profesionales de la Capoeira son incapaces de regular su propia actividad y certificar a las personas que son representantes de esta arte, y que, por ello, se requiere de la validación oficial. Ello, sin olvidar que detrás de la regulación se encuentra el componente de la administración de la riqueza una actividad como la Capoeira, riqueza que, en primera y última instancia, debería de pertenecer a las personas practicantes y profesionales de esta arte y no al Estado que, por muchas décadas, se encargó de perseguir y criminalizar esta práctica.

\section{Regular la cultura y la resistencia popular}

Si bien el trabajo ha discutido las disputas en torno a la Capoeira en el contexto brasileño, existen algunos elementos que podrían retomarse en torno a la discusión de otras expresiones culturales en Latinoamérica, así como la perspectiva política sobre la cultura de las poblaciones populares en este caso, las poblaciones afrobrasileñas. En este sentido, como se señaló desde un inicio en este trabajo, se ha privilegiado la perspectiva teórica poscolonial para identificar la manera en

\footnotetext{
${ }^{1}$ Andan diciendo por ahí. Andan diciendo por ahí. Que una ley ja se creó para reglamentar la Capoeira. Esa cosa se volvió. Quien llevó esa ley iHey! Quien llevó es ley iOh, ia, ia! Capoeira no jugo. Capoeira nació en el gueto y el mundo ya ganó"
} 
cómo los intentos de regulación de la Capoeira representan una forma de extractivismo de los saberes que detentan las personas profesionales de la Capoeira, incluyendo con ello, a las riquezas que estos saberes pudieran generar.

En este sentido, la acción del gobierno brasileño se encuadra en la manera en cómo los gobiernos latinoamericanos se relacionaba con la diversidad cultural de las poblaciones populares. “... a través del simple uso de la violencia, o por medio de la maleable ideología de la mixtura inclusiva, los Estados Latinoamericanos históricamente han mostrado una gran capacidad para acomodar las internas diferencias culturales, presentando sobre décadas una gran estabilidad de los lazos de pertenencia simbólica entre sus miembros". (Costa, 2016, p. 15). Es innegable que los intentos de regulación de la Capoeira, como las políticas dirigidas a esta arte, tienen la intención de integrarla dentro de la narrativa de la cultura nacional brasileña, sin que ello implique resolver las desigualdades históricas, ni respete los particulares modos de regulación que mantienen las personas profesionales de la Capoeira al interior de sus organizaciones ni en la ejecución profesional de su actividad cultural.

Esto, también tiene un referente histórico, pues, en el período de construcción del Estado nacional brasileño fue clave en el contexto de la recuperación de los símbolos culturales sobre los que se sostendría el discurso nacionalista de la identidad brasileña (Assunção, 2005; Abib, 2013). Así, durante el gobierno de Getulio Vargas, se recuperaron expresiones culturales otrora desdeñadas e incluso criminalizadas, un ejemplo fue la Capoeira y otro, la samba. Este espíritu de orgullo nacionalista por las expresiones culturales brasileñas encuentra una nueva versión en la recuperación de las actividades culturales por medio del instrumento de declaración del patrimonio. No obstante, en este contexto, no ha primado una lógica de negociación entre autoridades y personas profesionales de la Capoeira.

En contraste, la resistencia que han mantenido las personas profesionales de la Capoeira, que se ha mostrado, específicamente en este último intento de regulación, representa un movimiento político opuesto, que se en raíza en historia política de resistencia que ha signado a la Capoeira, como a otras expresiones culturales afrobrasileñas. Lo cual, también ha sido teorizado dentro de la tradición poscolonial de las relaciones entre autoridades y las poblaciones populares en el marco de la política cultural. Así, como lo señala Carvalho: "Dialogando con el tema de la resistencia simbólica y política, ya abordado por tantos autores, digamos que la marca fundadora de la cultura popular en América Latina ha sido su capacidad para resistir la presión de las élites para homogeneizar una cultura nacional desde la perspectiva de la cultura erudita occidental". (Carvalho, 2010, p. 44).

Sin lugar a duda, la arena política de la regulación de la Capoeira es un ejemplo importante sobre la forma en la que se desarrollan las resistencias y las negociaciones entre autoridades y poblaciones populares. Es una vez más, Carvalho (2010) quien define cómo se dan estas relaciones políticas desde la óptica de las resistencias populares:

Cuando hablamos de resistencia a las culturas populares, podemos pensar en dos procesos principales: por un lado, un choque abierto con el Estado que buscaba dirigir y controlar las expresiones simbólicas en una dirección diferente de los valores estéticos y espirituales de las clases populares. Una vez presionados para conformarse, los artistas populares se resistieron a la unilateralidad del Estado y negociaron posiciones, derechos y deberes, utilizando varias formas de organizar sus propios intereses artísticos. Por lo tanto, es posible concebir la tradición cultural popular como una tradición de instituciones culturales populares, con sus pedagogías y jerarquías distintas de las impuestas a la población a través del aparato ideológico del Estado. El otro modelo de resistencia consistía en aprovechar las lagunas, lagunas y ceguera de las élites 
estatales, que no percibían o no lo juzgaban de interés controlar ciertas expresiones simbólicas. Por lo tanto, era más fácil para las clases populares mantenerlas más tiempo a través de una estrategia consciente de ocultación, invisibilidad, disfraz o camuflaje. ( $p, 45)$.

En el caso de las personas profesionales de la Capoeira, con base en lo presentado, se podría pensar que se ubicarían dentro del primer modelo de la confrontación política. Tal vez en una transición hacia un modelo de fortalecimiento de los instrumentos y canales de negociación con las autoridades en aras de obtener más derechos y beneficios para las personas que conforman el gremio de personas profesionales de la Capoeira. No obstante, para lograr estos grados de empoderamiento político y con ello, un mayor rango de negociación sería necesario una mayor cohesión al interior de los grupos de Capoeira, así como la creación de una agenda común. Un importante tema que está pendiente y que, desafortunadamente, supera los límites de este trabajo.

Por otro lado, la resistencia hacia los intentos de regulación que manifiestas las personas que practican Capoeira, tiene un correlato espacial en cuanto a lo acontecido con las acciones que han sucedido en espacios vinculados con la Capoeira que fueron designados como espacios patrimoniales para la cultura de Brasil, ese es el caso del barrio del Pelourinho en la ciudad de Salvador, capital del estado de Bahía. Un barrio que, después de las acciones de recuperación y renovación, después de la declaración patrimonial, fue testigo de una gradual gentrificación (Zanirato, 2007, p. 39-42) de sus calles y espacios, pues la renta y los servicios de sus calles comenzaron a encarecerse. Esto ocasionó que varios de los residentes con menores recursos, tuvieran que buscar otros espacios para vivir en la periferia de la ciudad, en donde las rentas son más bajas (Zanirato, 2007, p. 43). Un fenómeno que ha acontecido en otros lugares emblemáticos de los centros históricos de las ciudades latinoamericanas (Swanson, 2007).

De tal forma, en el caso de las acciones gubernamentales que designan espacios con valor histórico y patrimonial, se han producido efectos que lejos de beneficiar a las personas que son objeto de estos nombramientos, pierden el acceso a las riquezas que suponen estos bienes. En el caso de los espacios históricos, como sucedió con las personas que habitaban en el Pelourinho, la cercanía y goce de la riqueza cultural de este barrio. Por otro lado, en el caso de los bienes inmateriales, se corre el riesgo de limitar la práctica y el ejercicio profesional de las actividades culturales que ostentan el nombramiento de patrimonio inmaterial. Una situación que no es exclusiva del caso de la Capoeira. Pues, en años recientes diversas expresiones culturales de la región del nordeste brasileño han sido objeto de declaratorias de patrimonio inmaterial, sin que el nombramiento suponga una un beneficio directo en la vida de las y los artistas.

Es en este contexto que se pueden comprender las reacciones de defensa que han manifestado las Mestras y los Mestres de Capoeira, quienes entienden que las normatividades del gobierno, aunque estén inciertas en un discurso bien intencionado, tienen como finalidad modificar las prácticas ancestrales que desarrollan las personas que son profesionales de la Capoeira. Esta lógica de resistencia, en gran medida se puede entender debido a la rigidez que la regulación supone sobre las prácticas culturales populares, como lo describió Sergio Costa (2016), en relación con las políticas de atención a las poblaciones quilombolas: “... la representación institucionalizada de las identidades culturales que se observa en las políticas multiculturalistas, significa un esfuerzo por encarcelar y congelar algo, la diferencia que sólo puede existir como algo móvil, flexible y variable” (p. 14).

De modo tal que, los modelos de relación que plantean los intentos de regulación de la Capoeira llevan implícita la intención de racionalizar las prácticas populares, las cuales, obedecen a una lógica diferente, sostenida sobre las propias regulaciones de los grupos de Capoeira, de la forma en las que se busca pensar desde las propuestas regulatorias. De tal modo, la tensión sociológica que se observa 
en el caso de la regulación de la Capoeira el irresuelto problema que supuso la conformación del gobierno brasileño después del período colonial, en el que se intentó atraer a los grupos populares afrobrasileños a las lógicas institucionales, sin que ello supusiera la resolución de la aguda desigualdad que se ocasionó con el proceso de esclavitud.

Es así como las poblaciones afrobrasileñas siguen sin gozar de un reconocimiento de fondo sobre sus prácticas y costumbres. Por el contrario, pervive el sentimiento de desconfianza y resistencia en torno al acercamiento institucional y a la supuesta valoración de sus bienes materiales y culturales. En este sentido, la Capoeira se volvió un caso ejemplar en torno a la resistencia de sus practicantes, pero, también debido a los intereses que rondan tras los intentos de regulación de su práctica. Uno de los principales temores de los practicantes, especialmente de los que se apegan a las raíces más tradicionales de la Capoeira, es el riesgo de que la Capoeira pierda su esencia y termine por convertirse en un espectáculo cultural, como lo sugiere Carvalho (2010) en los conceptos de espectacularización y canibalismo:

Los dos términos buscan expresar la percepción y la conciencia de que las culturas populares están siendo expuestas a un creciente y continuo movimiento de invasión, expropiación y depredación, básicamente conectado con la voracidad de las industrias del entretenimiento y el turismo y también con la cooptación de artistas populares por políticos regionales populistas. (p. 41).

De modo tal que, las futuras políticas en torno a la regulación de la Capoeira, si buscan salir del curso que se ha descrito, deberán de partir del reconocimiento de las propias formas de organización que poseen las organizaciones de profesionales de esta arte. Partir de las necesidades de las personas practicantes en vez de la imposición de necesidades vistas desde el ángulo de las autoridades, podría ser una ruta que construiría una política restitutiva en favor de los perjuicios históricos que pesan sobre las poblaciones afrobrasileñas desde tiempos de la colonia. Ese equilibrio de las fuerzas políticas podría ser un reconocimiento mucho más valioso que cualquier declaración de bien patrimonial, pues, debe recordarse que ya por sí misma, mucho antes de cualquier reconocimiento instituciones o gubernamental, la Capoeira ha sido valorada por las personas, dentro y fuera de Brasil, por su riqueza cultural y artística. Un logro que los Mestres y Mestras de Capoeira han logrado por sí mismos.

\section{Conclusiones}

Aunque las posturas de ambos bandos son muy claras, sigue pendiente la resolución de la propuesta de ley promovida por de Andrada. En apego a la historia de la incesante polémica sobre la regulación de la Capoeira, podríamos decir que, como sus antecesoras, la propuesta de ley terminará por ser desechada. No obstante, es posible que este no sea el último episodio que veamos sobre la intervención estatal en la regulación y ordenamiento de la práctica y enseñanza de la Capoeira. Lo que preocupa es el hecho de que se sigan realizando estos intentos de regulación sin la participación de las personas profesionales y practicantes de Capoeira.

Al respecto, no es que se eluda la intervención del Estado en la regulación de la práctica y enseñanza de la Capoeira, por el contrario, es deseable conformar un comité de observación y ordenamiento ético y laboral que supervise y legisle en torno a las personas que practican y enseñan Capoeira. Uno de los fines que tendría este órgano, sería responsabilizar jurídicamente a quien dañe o perjudique con sus acciones el bien público y el interés social que representa la Capoeira como 
patrimonio inmaterial de Brasil y de la humanidad. Es decir, así como se responsabiliza y castiga a quien daña un monumento o espacio histórico, es necesario que se proteja a quien, con sus acciones, dañe el patrimonio inmaterial de la Capoeira, así como a las personas profesionales de la Capoeira, quienes encarnan esta arte.

Sin embargo, este órgano debe de estar constituida por las propias personas profesionales de la Capoeira y no por agentes que son externos a la práctica de esta arte, como ha sucedido en el caso de las regulaciones que se han buscado impulsar, como es el caso de la PL 3640/2020. En este sentido, es necesario entender que cualquier propuesta de regulación o de ley que no incluya la participación de las personas que viven y practican Capoeira, será rechazada. Entonces, es necesario sustituir la perspectiva colonialista e impositiva hacia las personas capoeristas, por una perspectiva de derecho inclusivo que reconozca las capacidades y agencias de las personas capoeristas con respecto a sus derechos y obligaciones, así como en los medios para obtener su sustento y desarrollo profesional.

Por otro lado, es necesario destacar que ninguna de las políticas culturales ha avanzado en favor de las políticas reparatorias y acciones afirmativas en favor de las comunidades afrobrasileñas, quienes, en ocasiones se olvida, fueron quienes iniciaron con la práctica de la Capoeira, y quienes sufren, hasta el día de hoy, las inclemencias de la pobreza y la desigualdad. Con base en ello, se ha ignorado que la Capoeira es el resultado de una resistencia cultural en contra de un proceso histórico de marginación, que va desde las senzalas hasta las favelas, y que no se ha hecho lo suficiente en términos jurídicos y políticos por revertir las desigualdades crónicas e históricas que están en la raíz de la pobreza que viven las comunidades afrobrasileñas.

En otro plano, tenemos la cuestión laboral que pretende ser regulada por la ley, pues, en un contexto en el que se vive el agotamiento de los derechos laborales, con el crecimiento de las tasas de desempleo y de empleo precario en Brasil, las personas profesionales de la Capoeira sienten que, al querer regular su profesión, se les está obligando a pasar de ser personas emprendedoras a ser personas asalariadas. Desde la perspectiva de las personas profesionales de la Capoeira, éstas cuentan con las posibilidades de gestionar y administrar sus propios saberes y productos sin la necesidad de encontrarse en una relación patronal. Contrario a ello, las empresas buscan impulsar una terciarización de los servicios, buscando que las personas capoeristas ingresen a una lógica laboral que precarice sus condiciones de trabajo y les impida desarrollar sus propias oportunidades de empleo.

Hoy en día, las personas profesionales de la Capoeira pueden ser contratadas por medio del Cadastro Nacional de Pessoas Jurídicas ${ }^{2}$ (CNPJ), como microemprendedor individual. Un esquema que, si bien no ofrece garantías laborales, si les permite a las personas profesionales de la Capoeira emplearse en distintos trabajos al mismo tiempo. Con ello, en su carácter de personas que poseen los conocimientos de su arte, las personas capoeristas pueden comercializar su conocimiento, sus habilidades, pero no entrar en una valoración estándar de su tiempo de trabajo a cambio de un salario establecido, como sucedería en una relación patronal tradicional. Al final, el punto de discusión nos lleva al respeto de la autonomía y libertad laboral de las personas profesionales de la Capoeira.

Por último, aunque en primera instancia se debería de resolver el problema de la regulación de la Capoeira a nivel nacional, no se puede perder de vista que, al haber sido declarada Patrimonio Inmaterial de la Humanidad, es necesario que se cree un órgano que supervise el ejercicio y enseñanza de la Capoeira a nivel internacional. Si bien, esto nos lleva a terrenos que escapan de los límites

\footnotetext{
${ }^{2}$ En México, podría ser equivalente al sistema de contratación por servicios y pago de honorarios del Sistema de Administración Tributario de la Secretaría de Hacienda y Crédito Público.
} 
analíticos que hemos planteado, consideramos necesario discutir sobre la creación de instancias internacionales que vigilen y tutelen el ejercicio y práctica de la Capoeira en su carácter de patrimonio Inmaterial de la Humanidad.

\section{Referencias}

Abib, P. (2013). Mestres e Capoeiras Famosos da Bahia. EDUFBA. Assunção, M. (2005). Capoeira The History of an AfroBrazilian Martial. Routledge.

Carvalho J.J. (2010). Espetacularização' e ‘canibalização' das culturas populares na América Latina. Revista Anthropológicas, $\quad 21 \quad$ 39-76. https://periodicos.ufpe.br/revistas/revistaanthropologicas/article/viewFile/23675/19331

Constituição Da República Federativa Do Brasil [Const] artículo 5.1988. Brasil.

Costa. N. L. (2010) De ato marginal a Patrimonio Imaterial: analise das políticas culturais para a capoeira. En A. A. Canelas R. (Org) Políticas culturais no governo Lula. Universidade Federal da Bahia.

Costa, S. (2016). Freezing Differences: Politics, Law, and the Invention of Cultural Diversity in Latin America. Revista Brasileira de Sociologia do Direito, 3(2), 8-32, mai./ago. https://doi.org/10.21910/rbsd.v3n2.2016.54.

Costa S. y Boatcă M. (2010) La sociología poscolonial. Estado del arte y perspectivas. Estudios Sociológicos, 28(83), 335-338. https://doi.org/10.2307/20749174

Elias, Norbert (2009), El proceso de la civilización: investigaciones sociogéneticas y psicogenéticas. FCE.

Fonseca, V. (2014). A outra face da imaterialidade. O registro e o inventario como meios de preservação de Patrimonio cultural imaterial a partir do estudo de caso da Capoeira. Arquivos e esporte Revista do arquivo Nacional, 27(2), 106-124. http://revista.arquivonacional.gov.br/index.php/revistaacervo/article/view/443

Grosfoguel, R. (2016) Del «extractivismo económico» al «extractivismo epistémico» y al «extractivismo ontológico»: una forma destructiva de conocer, ser y estar en el mundo. Tabula Rasa. Bogotá, (4), 123-143. https://doi.org/10.25058/20112742.60

Lei no 12.288. Estatuto da Igualdade Racial. Dispositivos Constitucionais Pertinentes. Brasil, de 20 de julho de 2010.

Lube, G. M. (2011). "Genuinamente brasileña. La nacionalización y expansión de la capoeira como práctica social en Brasil Araucaria". Revista Iberoamericana de Filosofía, Política y Humanidades. Sevilla: Universidad de Sevilla, 13(26), 72-100. https://idus.us.es/handle/11441/46088;jsessionid=CB3BDD1E3300BD1219D918F052D5396 8 ?

Martínez, M.V. (2015) Dos versiones sobre Alejandro Magno en Diálogos de los muertos de Luciano. Una revisión de la memoria literaria El hilo de la fábula. Revista anual del Centro de Estudios Comparados (15), 209-218. https://doi.org/10.14409/hf.v0i15.5041

Mignolo. W. (2010) Desobediencia epistémica: retórica de la modernidad, lógica de la colonialidad y gramática de la descolonialidad. Ediciones del signo.

Pires, O. J. y Pinheiro Leal, L. A. (2009). Capoeira, identidade e gênero. Ensaios sobre a história social da Capoeira no Brasil. Universidade Federal da Bahia. 
Proposta de Lei PL - 3640/2020. Dispõe sobre o reconhecimento do ofício de Profissional de Capoeira e dá outras providências. Câmara dos Deputados. Brasil, 3 de julio de 2020.

Rector, M. (2008). Capoeira: el silencioso lenguaje de los gestos. Signo y Pensamiento, xxvii (52), 184-194. https://www.redalyc.org/articulo.oa?id=86005214

Rede Nacional de Ação da Capoeira [RENAC] "Manifesto contra a Regulamentação Da Capoeira e Contra o PL 3640/2020”. https://bit.ly/3jFrnOu

Serna, L. E. (2018). Os jogos políticos da capoeira: análisis de la política cultural nacional e internacional sobre la capoeira. En: R. Nascimento, R. y V.S. González (Coords.). A Capoeira: Revista de Humanidades e letras, 4(2). 142-167. https://bit.ly/3cWpFXD

Swanson, Kate (2007) Revanchist Urbanism Heads South: The Regulation of Indigenous Beggars and Street Vendors in Ecuador. Antipode. 39(4), 708-728. https://doi.org/10.1111/j.14678330.2007.00548.x

Talmon-Chvaicer, M. (2008). The Hidden history of Capoeira: A collison of culture in the Brazilian battle dance. University of Texas Press.

Zanirato, S. H. (2007). A restauração do pelourinho no centro histórico de Salvador, Bahia, Brasil. Potencialidades, limites e dilemas da conservação de áreas degradadas. História, cultura e cidade. $H A O L$, , (14), 35-47. https://dialnet.unirioja.es/servlet/articulo?codigo $=2529031$ 